\title{
Assessment of long-term anticoagulation in patients with a continuous-flow left-ventricular assist device: A pilot study
}

\author{
Douglas Jennings, PharmD, BCPS, Jane McDonnell, PharmD, and Jessica Schillig, PharmD, BCPS, \\ Detroit, Mich
}

The HeartMate II, developed by the Thoratec Corporation (Thoratec Corporation, Pleasanton, Calif), is a continuous axial-flow left ventricular assist device that has shown promising results for extended mechanical circulatory support. Patients with this device usually receive long-term anticoagulation to prevent thrombosis and ischemic stroke; however, patients with this device also seem to have an elevated risk of bleeding. ${ }^{1}$ Anticoagulation must therefore be optimized in these patients to protect against thromboembolism but also minimize bleeding risks.

Currently, data describing the long-term outpatient anticoagulation in patients with the HeartMate II are limited. The purpose of our pilot study was to characterize the long-term outpatient anticoagulation regimen for HeartMate II recipients with regard to time within the therapeutic international normalized ratio (INR) range, weekly warfarin dose, and incidences of bleeding and thromboembolic events.

\section{MATERIALS AND METHODS}

This study included patients with the HeartMate II implanted from June 1, 2008, to May 31, 2009, at Henry Ford Hospital, an 806-bed tertiary care teaching facility. Data collection included patient demographic data, medical history, laboratory values, and interacting medications. The primary end point measured was time within therapeutic INR range, defined as an INR of 2 to 3 during the period of data collection. The historical average time in the therapeutic range for the overall clinic population was the comparator group. Secondary end points included time above and below the therapeutic INR range, median weekly warfarin doses, and incidences of thromboembolic and bleeding events. Bleeding was defined according to the Thrombolysis in Myocardial Infarction study criteria, and thrombosis was defined as any newly diagnosed stroke, venous thromboembolism, or device thrombosis. Data were gathered from computerized progress notes from the institution's outpatient pharmacist-managed anticoagulation clinics. The number of patient days within, above, and below the therapeutic INR range was calculated according to Rosendaal and colleagues' method for linear interpolation. ${ }^{2}$

From the Department of Pharmacy Services Henry Ford Hospital, Detroit, Mich. Disclosures: Authors have nothing to disclose with regard to commercial support. Presented as a research abstract at the American College of Clinical Pharmacy Annual Meeting, Austin, Texas, Sept 18, 2010.

Received for publication Sept 3, 2010; revisions received Sept 22, 2010; accepted for publication March 28, 2011; available ahead of print April 29, 2011.

Address for reprints: Douglas Jennings, PharmD, BCPS, Clinical Pharmacy Specialist, Cardiovascular Intensive Care Unit, Henry Ford Hospital, Department of Pharmacy Services, 2799 W Grand Blvd, Detroit, MI 48202 (E-mail: djennin1@hfhs.org).

J Thorac Cardiovasc Surg 2011;142:e1-2

$0022-5223 / \$ 36.00$

Copyright (c) 2011 by The American Association for Thoracic Surgery doi:10.1016/j.jtcvs.2011.03.029

\section{RESULTS}

A total of 16 patients (average age, 53 years; 62\% African American; $81 \%$ male; $31 \%$ bridge to transplant) yielded 576 INR values and 5004 days of follow-up. The average time in the therapeutic range for HeartMate II recipients was $51 \%$ (range, $22 \%-88 \%$ ), which is significantly worse than the $68 \%$ time within range for our overall clinic population. Average times above and below the therapeutic range for the HeartMate II group were $17 \%$ and $32 \%$, respectively. Every patient had at least one nontherapeutic INR value, and the median time within range was $49 \%$. The median weekly warfarin dose for these patients was $35 \mathrm{mg}$ (range, 16-70 mg). There were no outpatient bleeding episodes. One patient had a transient ischemic attack as an outpatient (INR 1.6 at the time).

\section{DISCUSSION}

Our study suggests that HeartMate II patients may spend less time in their target INR range than the overall population at our anticoagulation clinic. The reasons for this deviation are unclear. Previous studies have demonstrated the potential of the HeartMate II to alter the coagulation cascade by inducing a deficiency of von Willebrand factor. ${ }^{1}$ It is possible that this device could produce other physiologic changes in the coagulation system that might influence the pharmacodynamic response to warfarin. Additionally, pharmacogenomic mutations may also have influenced warfarin response in these patients.

Previous reports describing anticoagulation in patients with the HeartMate II are limited. John and coworkers ${ }^{3}$ followed up 45 HeartMate II recipients for 7 months and reported an overall median INR range of 1.6 to 2.0, whereas Boyle and associates ${ }^{4}$ followed up 331 patients with the device as a bridge to transplant for 6 months and reported a median INR value of 2.1. Neither of these studies calculated a time within range with linear interpolation. Furthermore, both studies only recorded INR values once a month or when a clinically significant event occurred (eg, bleeding). In contrast, our study followed up patients for as long as 1 year and measured INR values at least monthly, or as frequently as weekly if patients were out of range. We believe that this close monitoring increased the ability of our study to detect subtle fluctuations in the anticoagulation of these patients.

Our study has several limitations that warrant further discussion. First, it is a single-center, retrospective analysis. Also, baseline characteristics for the comparator group 
are not available, because the time within range for these patients was drawn from historical data obtained from our anticoagulation clinic. Finally, although linear interpolation is a well validated and accurate method for estimating time within the therapeutic INR range, it is still possible that not all fluctuations in the INR were detected by this analysis.

In conclusion, the results of our pilot study suggest that HeartMate II recipients may spend a significant amount of time with values outside the target INR range. We saw this deviation despite relatively normal warfarin dosage requirements. Additional studies exploring the etiology of this potentially altered pharmacodynamic response are warranted. Practitioners implanting left ventricular assist devices should closely monitor the INR of these patients to ensure optimal levels of anticoagulation.

\section{References}

1. Uriel N, Pak SW, Jorde UP, Jude B, Susen S, Vincentelli A, et al. Acquired von Willebrand syndrome after continuous-flow mechanical device support contributes to a high prevalence of bleeding during long-term support and at the time of transplantation. J Am Coll Cardiol. 2010;56:1207-13.

2. Rosendaal FR, Cannegieter SC, van der Meer FJ, Briët E. A method to determine the optimal intensity of oral anticoagulant therapy. Thromb Haemost. 1993;69:236-9.

3. John R, Kamdar F, Liao K, Colvin-Adams M, Miller L, Joyce L, et al. Low thromboembolic risk for patients with the Heartmate II left ventricular assist device. J Thorac Cardiovasc Surg. 2008;136:1318-23.

4. Boyle AJ, Russell SD, Teuteberg JJ, Slaughter MS, Moazami N, Pagani FD, et al. Low thromboembolism and pump thrombosis with the HeartMate II left ventricular assist device: analysis of outpatient anti-coagulation. J Heart Lung Transplant. 2009;28:881-7.

\section{An unusual case of chyloptysis}

Rebecca Tregunna, MBBS, BSc, ${ }^{\mathrm{a}}$ Elizabeth Belcher, MRCP, FRCS, PhD, ${ }^{\mathrm{a}}$ Paul Cane, FRCPath, ${ }^{\mathrm{b}}$ and Loic Lang-Lazdunski, MD, PhD, ${ }^{\mathrm{a}}$ London, England

Chyloptysis is rare and usually occurs spontaneously secondary to disorders of the mediastinal lymphatic system. We present a case of chyloptysis after cervical mediastinoscopy and biopsy of mediastinal lymphadenopathy.

\section{CLINICAL SUMMARY}

A 59-year-old man presented with a 3-month history of a cough producing white sputum streaked with occasional minor hemoptysis. His medical history was unremarkable other than a pericardial effusion, not noted to be chylous in nature and of unknown cause, requiring percutaneous drainage without complication 10 years previously. $\mathrm{He}$ was a nonsmoker. Examination results were unremarkable with no evidence of yellow nail syndrome. Computed tomography (CT) of the chest demonstrated widespread paratracheal lymphadenopathy, anterior mediastinal mass, and normal lung fields (Figure 1, $A$ ). Subsequent bronchoscopy results were normal. Cervical mediastinoscopy confirmed extensive mediastinal lymphadenopathy. Chyle was noted to reflux on manipulation of tissues; however, no evidence

From the Departments of Thoracic Surgery ${ }^{\mathrm{a}}$ and Histopathology, ${ }^{\mathrm{b}}$ Guy's Hospital, Great Maze Pond, London, England.

Disclosures: Authors have nothing to disclose with regard to commercial support. Received for publication Oct 22, 2010; accepted for publication March 21, 2011.

Address for reprints: Loic Lang-Lazdunski, MD, PhD, Department of Thoracic Surgery, Guy's and St Thomas' NHS Trust, Great Maze Pond, London, SE1 7RT (E-mail: loic.lang-lazdunski@gstt.nhs.uk).

J Thorac Cardiovasc Surg 2011;142:e2-3

$0022-5223 / \$ 36.00$

Copyright (c) 2011 by The American Association for Thoracic Surgery doi:10.1016/j.jtcvs.2011.03.012 of elevated lymphatic pressure or hemorrhage was noted. Biopsy of mediastinal nodes (stations 2 and 4) was without complication and showed only reactive changes, with no evidence of granuloma formation or malignancy after histopathologic examination.

After this procedure, the patient presented again with a worsening cough and shortness of breath. He now described his sputum as being of "fried egg" appearance. Analysis of sputum confirmed chyloptysis (triglyceride, $14.7 \mathrm{mmol} / \mathrm{L}$; cholesterol, $2.0 \mathrm{mmol} / \mathrm{L}$ [ratio 7.4:1]). Repeat CT of the chest showed a $90-\mathrm{mm}$ anterior mediastinal mass with patchy parenchymal opacification in the lingula and left lower lobe, but no evidence of pleural effusion (Figure 1, $B$ ). Lymphangiography was not undertaken. The patient underwent median sternotomy and resection of this anterior mediastinal mass. At operation, chyle was noted draining from the cut tumor surface. Multiple small vessels were noted between the mass and hilum of the left lung, which were divided using the Harmonic scalpel; however, the mass did not invade into the lung parenchyma, and pulmonary resection was not deemed necessary. BioGlue (CryoLife, Europa Ltd, Surrey, UK) was applied over the resection area in an attempt to reduce the risk of chylothorax in the early postoperative period.

Histopathologic examination showed predominantly adipose tissue interspersed with cystically dilated spaces containing grey, chylous fluid and multiple congested blood vessels with focal punctate hemorrhage confirming a typical lymphangioma (Figure 2). The patient made a satisfactory postoperative recovery with no further chyloptysis at 7 months postoperatively. 